\title{
Insights into teachers' views on sharing ways of knowing and ways of teaching between and beyond existing disciplines
}

\author{
Anne Algers and Linda Bradley
}

\begin{abstract}
Since academic teachers belong to different disciplines and thus discourses, they have different ways of knowing and teaching. Recent societal challenges call for thinking beyond boundaries and re-visiting academic practices. The purpose of this study is to investigate how academic teachers view sharing of knowledge and teaching. The study is based on survey data from eight faculties and interviews of teachers from each of these faculties at the University of Gothenburg. The results show that professional development courses in higher education teaching and learning, as well as open practices, and collaboration between academic disciplines and society are practices, which Galison (1997) termed trading zones. These trading zones are sources of learning to theorize and to facilitate exchange among peers with the potential to develop knowledge, identity and moral commitments necessary to address societal challenges. Further, the results suggest that universities need to scaffold these sharing practices. The findings inform how academic teachers' practices can be transformed into sharing between and beyond academic disciplines.
\end{abstract}

Keywords: collaboration with society; open practices; professional development courses; societal challenges; trading zones

Received 28 April 2020; revised version received 26 October 2020; accepted 26 October 2020. Corresponding author: Anne Algers, University of Gothenburg, Sweden (anne.algers@gu.se).

\section{Introduction}

Academic practices have traditionally been divided into disciplines hosting an established set of problems, discourse, and content areas. However, the significance of disciplines is being increasingly questioned, especially where multidisciplinary collaboration is required to address real-world problems (Trowler, Saunders, \& Bamber, 2012) and to develop 'new fields of inquiry and forms of knowledge production' (Hannon et al., 2018, p. 1425). As the concept of discipline is under scrutiny, researchers have called the phenomenon of adhering to disciplines too rigidly academic tribes (Becker, 1989), silos (Kreber, 2009) or tribes and territories 
(Trowler et al., 2012). These terms have become metaphors, defining how knowledge is organised in disciplinary subgroups in universities and how cultures of academic fields have their roots in different knowledge characteristics. This in turn suggests a strong sense of disciplinary belonging and identity that can undermine collaboration across disciplines (Peel, 2011).

Gilbert (2016) suggested that there are good reasons for disrupting traditional ways of doing and to encourage thinking and acting beyond traditional identities and disciplines. She argued for a paradigm shift in ways of knowing and ways of teaching on three different levels: First, science should neither be treated separately from human thought (and values) nor from education. Second, teaching should not be based on mass instruction of students through pre-determined steps that are aimed at mastering topics of little interest to them. Third, Gilbert (2016) stressed that society cannot be 'treated as an entity, as something that has always existed' (p. 198). Such a paradigm shift towards de-siloing disciplines within the academy is often limited by existing but unnoticed or unexamined assumptions and views, suggesting that individuals and institutions become immune to change (Kegan \& Lahey, 2009). In fact, the de-siloing metaphor 'captures the concern of interdisciplinary curriculum design, and marks an orientation to work with multiple domains of knowledge and terminology' (Hannon et al., 2018, p. 1432).

Numerous studies have focused on how digitization increases interaction and collaboration within and beyond the academy but, since both are based on social relations, more focus should be on the conditions of these individuals and human aspects of their social interaction (Castañeda \& Selwyn, 2018).

This study is set out to identify academic teachers' assumptions and views about knowledge and education. In addition, we focused on better understanding how academics engage in new ways of participating across boundaries and in scaffolding students' ability to think between and beyond existing disciplines, especially outside of the university context. Galison (1997) coined the phrase trading zone as a way to explain how physicists from different disciplines collaborate; in other words, how heterogeneous actors were operating with a joint interest and common ground in mind. The concept of educational trading zone, as a metaphor, describes the space where ideas about learning and teaching are shared within and between disciplines (Mills \& Huber, 2005). Three primary reasons that impede trading within and between discipline are suggested: 1) the low status of education as a discipline, 2) disciplinary pedagogies embedded in academic identity, and 3) resistance to engage with new visions of teaching professionalism (Mills \& Huber, 2005).

In the following section, we give an overview of related research, followed by our argumentation for rethinking current practices, in the light of the findings of our study. 


\section{Ways of knowing and ways of teaching}

Scientific consensus implies collective judgment, position, and opinion of the community of scientists in a particular field of study or discipline. Kuhn (1962) proposed that scientific consensus was never truly a matter of pure logic or pure facts but worked out in the form of paradigms, which were interconnected theories and underlying assumptions about the nature of theory, the goals of science, and the consensus on appropriate inquiry that connected researchers in a given field. Along these lines, paradigm shifts have been discussed as major shifts in scientific practices.

Biglan (1973) conducted a systematic classification of disciplines based on multi-dimensional analysis of how academic scholars judge different subject areas on a set bi-polar scale. These dimensions of paradigm support Kuhn's theory that some disciplines belong to a single paradigm with consensus about both content and method, whereas other disciplines lack consensus (Kuhn, 1962). Biglan identified three characteristics: 1) a distinction between hard (natural sciences) and soft (humanities and education); 2) a dimension of application (the distinction between pure and applied); and 3) a dimension of concern with life systems (a life/non-life distinction). Research on this classification system indicates that hard fields emphasise the professional preparation of students through the learning of facts, principles, and concepts. Soft fields, in contrast, emphasise general knowledge, personality development through the promotion of critical thinking and reasoning, communication, as well as formation of values (Rotidi et al., 2017).

There are other concepts identifying and at the same time questioning the understanding of what constitutes a specific disciplinary area. One such a concept is the so-called threshold concept theory, that is 'understanding or interpreting or viewing something without which the learner cannot progress' (Meyer \& Land, 2005 , p. 1). The value of threshold concepts has been questioned due to subjectivity of descriptions of each characteristic (O’Donnell, 2010). To date, it has been difficult to measure threshold crossings and there is a need for a more convincing body of evidence for it to be valid (Nicola-Richmond et al., 2018) and thus for being able to identify what is important within a specific discipline.

If we return to how views on disciplinary boundaries for ways of teaching has developed, John Dewey's (1916) seminal insights are as relevant today as ever. He indicated the importance of teaching students how to integrate and generalise knowledge in higher education: 'the end of education is not the bare reception and storage of information, but the formation of personal powers of attention, memory, observation, abstraction, and generalisation' (p. 67).

A number of academics have suggested that views on teaching are closely linked to their views on knowing (e.g., Kember, 1997). Shulman (2005) argued that pedagogies are pervasive in that they are transferable and can be 'traded' across disciplines and argue for participating in trading zones (Gardner \& Shulman, 2005). 
The concept of trading zones is a way of describing a space in which ideas about learning and teaching are shared within and between disciplines, and this trading is suggested as a response to rigidity of habits and for improvement of teaching and learning in other disciplines (Shulman, 2005).

Teachers' individual views and intentions have also been found to affect their teaching approaches. Prosser et al. (2005) investigated university teachers' understanding of their subject matter and how this subject matter was structured in their teaching, depending on whether they had an atomistic view on their subject or a more holistic view. They reported that teachers with an atomistic view on their subject resulted in a more surface type of learning among students (Prosser \& Trigwell, 1999).

In the next section, we discuss why disciplinary and sometimes even individual views on knowing and teaching may limit or hinder our ability to address complex societal problems, especially where rethinking assumptions is warranted.

\section{Rethinking ways of knowing and teaching}

In his argumentation that knowing should be understood as 'a way of doing', Biesta (2007, p. 13) refers to Dewey's (1920) work in which knowing is based on experiences; specifically, feedback systems between human inquiry, actions and consequences in their environment. The kind of hypotheses that are essential for rigorous conduct inquiry are termed 'ends-in-view' (Dewey, 1920, p. 223). That means academics neither in their role as researchers, nor in their role as teachers should uncritically accept conventional problem definitions or predetermined ends.

Some complex issues such as sustainable development, health, and ethics, are particularly in need of a collective and participatory angle of entry (Wals, 2007), since they are contested areas of concern that are difficult to predict and at risk of being more opinion-based than evidence-based. Further, the ideas of looking at disciplines as hosting a specific body of knowledge with its own procedures have been challenged in that there is little that is unique for a specific discipline (Trowler et al., 2012). Rather, we turn to theories of boundary crossing and expansive learning, characterising both activities to reach consensus between disciplines and activities that change values and views (Engeström \& Sannino, 2010).

Engeström and Sannino (2010) described expansive learning as an integration of two directions, one that is learning in networks of interconnected individuals across boundaries that share a willingness to understand a contested issue. The other direction tackles issues such as subjectivity, emotion, identity, and moral commitment. Thus, in expansive learning the boundaries are hard to draw, actors from different disciplines are coming together and it is about learning something that is not yet there. This view on learning assumes that the learners' autonomy and self-direction is acknowledged and that understanding is socially 
constructed (Thomas \& Brown, 2011). When societal questions are complex and need to be addressed from different perspectives (Gilbert, 2016; Wals, 2007), expansive learning and trading zones can emerge as new cultures of learning.

\section{Aim and research questions}

The aim of the study is to contribute to the understanding of how academic teachers' disciplinary work is organised and to identify the trading zones where transdisciplinary sharing is taking place.

Research questions:

1. How do academic teachers' in different disciplines characterise ways of knowing and ways of teaching?

2. What are academic teachers' views on sharing within, between, and beyond existing disciplines?

3. Do academic teachers believe that sharing creates new ways of thinking and teaching?

\section{Methodology}

In order to investigate academic teachers' views on ways of knowing and ways of teaching within, between and beyond different disciplines in universities, a mixed method approach was adopted. First, a survey was designed, covering questions about views on teaching in higher education. The survey contained 11 questions (see Appendix 1). Initially, there were background questions about disciplinary belonging and teaching experience in order to identify differences between disciplines and teaching experience. In addition, disciplinary characteristics were identified through questions about teaching methods, sharing cultures (collegial discussions as well as digital sharing), and teaching principles based on Laurillard's (2012) work on teaching design. Finally, there were questions about implications and experiences of the courses in higher education teaching and learning. The question types were a combination of a Likert scale for the question on teaching principles, open text fields for one of the questions about the courses in higher education teaching and learning, and the rest were answered by ticking one or several options. We also provided the possibility to add alternatives to preselected choices.

After the analysis of the survey, follow-up interviews were conducted to obtain a more in-depth understanding of the views of the teachers' ways of knowing and ways of teaching and to identify where transdisciplinary sharing is taking place. 
Two central aspects derived from the survey to be included in the interview questions are collaboration across disciplines and engaging in sharing practices. Here, openness and digital learning are two topical areas connected to collaboration and sharing.

We approached academics at the University of Gothenburg, hosting eight faculties with 38 departments, covering a wide variety of disciplines in higher education. All of the academics surveyed had participated in professional development courses in higher education teaching and learning offered at the university. The courses consist of three foundational courses, each covering various aspects of teaching theories and methods as well as student learning approaches, with the aim to support teachers in their teaching practice of writing learning objectives, designing, assessing and examining courses. Since the courses are open for all teachers at the university, there is a mix of teachers belonging to various disciplines, which caters for fruitful discussions among the course participants, where different contexts and views are compared. Participation in these types of courses have become a requirement for employment as a lecturer, or for promotion to professor at most Swedish universities (Ödalen et al., 2018). In addition, the courses offer a rare opportunity for teachers across a wide variety of disciplines to come together and share ideas about teaching and learning.

\section{Survey}

The survey was distributed via email to 526 academic teachers from various disciplines at the University of Gothenburg who had attended courses in higher education teaching and learning as part of their professional development, during a period of five years, from autumn 2013 to spring 2018. The academics were guaranteed anonymity, and could access the survey at Webropol via a link and could voluntarily reply. Responses were obtained between June and August 2018. From the total number of emails, including two reminders, 487 persons were reached. The 39 who were not reached were either on leave, parental or sick leave, or had finished working at the university. A total of 155 persons responded, leaving a response rate of $32 \%$. It is an undeniable fact that since our respondents were recruited from courses stretching several years back it affected the response rate.

In the survey analysis, data was analysed and reported with descriptive statistics (\%) and bivariate tests from cross tabulation were done with Pearson's Chi-square test, including effect sizes for Cramer's V.

\section{Interviews}

To obtain an in-depth understanding of the survey responses, 16 survey respondents, two respondents from each faculty, were recruited for individual semistructured interviews. The two researchers and authors of this article interviewed eight respondents each, one from each faculty. The interviews were audio recorded and lasted between 20 and 30 minutes. In 19 interview questions, the respondents 
expanded on the themes in the survey, such as views of research and teaching, the meaning of knowledge, collegial collaboration, engaging in sharing and openness, digital learning, and collaboration with society including public outreach. Subsequently, the interviews were transcribed in their full length and the documentation included who spoke, what was said, and, in some cases, how it was said. Sixteen interviews were in Swedish and two in English. After transcription, the data was anonymized. Responses were organized under tentative themes, in order to identify consistencies and differences. The outcomes were analysed individually by the two researchers and then cross-examined and analyzed. From the analysis prominent themes emerged in consensus from the interviews. Citations of relevance were identified as excerpts and citations under each theme and Swedish excerpts were translated into English.

\section{Findings}

The mixed-method study is based on survey and interview data that provides a picture of how ways of knowing and ways of teaching are characterized in different disciplines and how sharing within, between and beyond their disciplines are viewed.

\section{Analysis of survey}

The data displayed a wide span of disciplines of respondents representing all eight faculties at the University of Gothenburg according to this distribution: Business, Economics and Law (23), Education (18), Fine, Applied and Performing Arts (17), Humanities (17), IT (6), Medicine (36), Science (19), Social Sciences (20). The majority of the respondents had long teaching experience; with a minimum of teaching for two years and the majority for more than 10 years.

\section{Teaching methods in disciplines}

Although teachers in different disciplines encounter students both individually as well as in small and large groups, our data showed that the most common teaching method in all disciplines was the lecture, which was used across every discipline. Seminars (95\% soft $/ 71 \%$ hard, $\chi 2(1, \mathrm{~N}=155)=17.1, \mathrm{p}<0.001$, medium effect), workshops $(63 \%$ soft $/ 31 \%$ hard, $\chi 2(1, N=155)=14.8, \mathrm{p}<0.001$, medium effect $)$, and student presentations ( $87 \%$ soft $/ 64 \%$ hard, $\chi 2(1, \mathrm{~N}=155)=11.7, \mathrm{p}<0.001$, medium effect) were more used in soft sciences. Laboratories (23\% soft/59\% hard, $\chi 2(1, \mathrm{~N}=155)=20.0, \mathrm{p}<0.001$, medium effect $)$ were more used in hard sciences. Group work $(86 \%$ soft $/ 72 \%$ hard, $\chi 2(1, \mathrm{~N}=155)=4.7, \mathrm{p}=0.031$, small effect $)$ and roleplay $(27 \%$ soft $/ 13 \%$ hard, $\chi 2(1, \mathrm{~N}=155)=4.0, \mathrm{p}=0.045$, small effect $)$ were more frequently used in soft sciences and response technology exercises (9\% soft/20\% hard, $\chi 2(1, \mathrm{~N}=155)=4.1, \mathrm{p}=0.043$, small effect $)$ more in hard sciences. 


\section{Using formative assessment across disciplines}

Formative assessment was a procedure that was used across the disciplines. The concept has gained increasing attention in higher education as an intention to stimulate further development as part of the learning process (Black \& Wiliam, 2009). However, a comparison between soft and hard disciplines was significant with $64 \%$ of teachers in soft disciplines using formative assessment versus only $41 \%$ of teachers in hard disciplines $(\chi 2(4, \mathrm{~N}=155)=14.3, \mathrm{p}=0.006$, medium effect.

\section{Encouraging meta-cognitive discussions}

Meta-cognitive discussions about content and critical discussions as a way to teach conceptual understanding was more frequently used in faculties of education and art than for example in science and medicine. A comparison between soft and hard disciplines showed in the same vein that $72 \%$ of teachers in soft disciplines and only $41 \%$ of teachers in hard disciplines $(\chi 2(4, \mathrm{~N}=155)=23.0, \mathrm{p}<0.001$, medium effect) encourage meta-cognitive discussions about content.

\section{Sharing in open access}

In terms of open sharing, academics were generally in favour of sharing their work. Academic teachers from hard disciplines publish more in open access journals compared to soft disciplines $(76 \%$ hard $/ 44 \%$ soft, $\chi 2(1, \mathrm{~N}=155)=15.2, \mathrm{p}<0.001$, medium effect). 'Life' disciplines compared to 'non-life' disciplines also publish more in open access journals $(64 \%$ life $/ 47 \%$ non-life, $\chi 2(1, \mathrm{~N}=155)=4.3, \mathrm{p}=0.037$, small effect), and pure disciplines reuse others' open material more often compared to applied disciplines (65\% pure/44\% applied, $\chi 2(1, \mathrm{~N}=155)=5.7, \mathrm{p}=0.017$, medium effect).

\section{Collegial pedagogical discussions}

Concerning collegial discussions about teaching, medicine sticks out as a discipline where higher education pedagogy is not as frequently discussed among teachers (53\% agree that pedagogy is discussed inside departments and only $31 \%$ outside the department). Further, pedagogical discussions among colleagues at the department were not so frequent in other hard disciplines either, whereas teachers in disciplines that are categorised as soft strongly claim that they discuss pedagogies with colleagues within the department. The difference between hard and soft disciplines is statistically significant concerning pedagogical discussions within the department ( $92 \%$ soft $/ 63 \%$ hard, $\chi 2(4, \mathrm{~N}=155)=13.9, \mathrm{p}=0.008$, medium effect) but not outside the department $(58 \%$ soft $/ 45 \%$ hard, $\chi 2(4, \mathrm{~N}=155)=6.8, \mathrm{p}=0.147$, medium effect). 


\section{Learning about teaching methods}

$74 \%$ reported that the courses in higher education teaching and learning had contributed to new knowledge about teaching methods which they use today. There was a significant difference between how the respondents reported on their learning, depending on type of discipline; $67 \%$ from soft disciplines and $84 \%$ from hard disciplines $(\chi 2(3, \mathrm{~N}=155)=7.9, \mathrm{p}=0.048$, medium effect $)$ found that the courses in higher education teaching and learning had contributed to knowledge about teaching methods that they were not aware of before and which they use today.

\section{Analysis of interviews}

The respondents had an average of 14 years of teaching in higher education, ranging from four to 28 years of teaching experience, which corroborates the survey results. Concerning the distribution of time of work activities, the respondents were generally both teaching and researching to varying degrees, ranging from $10 \%$ to $75 \%$ research. Three were only teaching and currently not involved in any research.

The following paragraphs give an account of the analysis of the interviews, together with quotes from the respondents that capture the essence of the respondents' views. Identification of which faculty the interviewee comes from is in brackets.

\section{Defining knowledge}

When the respondents were asked to define knowledge, it was generally understood as information being processed in order to become knowledge. In a similar vein, knowledge was expressed as a process: 'an endeavour to know more' (respondent from Education), and includes knowing in the sense of being acquainted with and knowledge as context bound:

Knowledge can take so many expressions - much of the theoretical knowledge can e.g. be embodied. I think of what we are doing in our institution, where we have research, for example, in the field of craftsmanship, where it is about the knowledge of the hand, which is an area that has been a little overlooked in science. (Science)

Knowledge depends on context, what context you are in and what is at stake $[\ldots]$ it is an attempt to understand and handle the outside world better. (Humanities)

Collaboration is very important because people from various disciplines have different perspectives on the subject [...] new questions and new angles are raised and we can also place the work we have done in new situations and contexts [...] (Art) 


\section{Threshold concepts}

The respondents did not bring up threshold concepts within disciplines as an enabler or constrainer for sharing but rather that disciplinary views or identity potentially constrain collaboration. On the other hand, respondents valued threshold concepts in teaching and learning as transferable between disciplines. On the question about collaboration between disciplines:

There are some thresholds sometimes because we speak different languages, which is not linguistic so to speak, and you can sometimes have a slightly different view on which research questions should be in focus. (Education)

I think the whole idea of constructive alignment in education is very good [...] I learnt this in the cross-disciplinary professional development courses [...] It is quite obvious [to align learning objectives to teaching and examination] if you think about it, but it was good to get a concept for it. (Humanities)

\section{Teaching as a vital activity}

Although the respondents claimed that teaching is considered less prestigious than research, teaching is still a vital activity for academics in higher education that is also demanding and requiring self-confidence. To the question of 'What is good education?' most respondents (13) had a student perspective in mind, with responses such as 'When students understand my intentions' (Fine, Applied and Performing Arts), 'I'd like to meet the students at the level where they are' (Social Sciences), 'Being enthusiastic and creating an interest, curiosity and a process for learning' (Science). On the other hand, two respondents had a teacher perspective in their response such as 'a competent teacher who encourages students and likes to be a teacher' (Science) and 'a teacher who has a good voice and is engaging for students' (Humanities).

\section{Knowing through participation}

Three respondents specifically articulated that knowledge is something that is not only transmitted in teaching but something that is developed through participation:

I think I received a more open view of how to make acquisition happen and whose responsibility it is. That knowledge is better achieved if the student is active in that search. (Medicine) 
My point is not to directly transfer the knowledge of anything but rather leaving the students with some tools where they can start thinking about the information they get. (Social sciences)

We should not only inform the students about our research; they must be part of the research environment in a clearer way. As an example, the master's students can be involved in a research project run by the research group - a lot of fun stuff is waiting here! (Art)

\section{Engaging students in decision making}

Some of the respondents even highlighted the importance of representation; that teachers give students a chance to be heard and participate in analysis and decision making.

I think it is very important that you, as a teacher, give those you are dealing with [the students] a voice. Good teaching is dialogical and based on listening $[\ldots]$ (Education)

My point is not to give them the direct knowledge of anything but to leave the students with certain tools to start thinking about the information they receive, what is the basis for the tools we use to end up in the logic or in the rational or in the analytical stance of our positions. (Social sciences)

\section{Impact of courses in higher education teaching and learning}

Half of the respondents found that participating in the courses in higher education teaching and learning has changed their view on knowledge (the respondents were equally divided between hard/soft and pure/applied disciplines). The courses contributed with time for reflection on knowledge and pedagogical development. Other respondents suggested that fruitful learning happens in meetings between colleagues from different disciplines and epistemologies within the courses:

It is clear that, in this way, one is reminded that there are different ways to build knowledge - that there are different ways to teach; that there are different areas of knowledge that place different demands. (Science)

The fact that the respondents made use of the pedagogical ideas achieved from their professional development courses in higher education teaching and learning and published their findings in higher education journals corroborates the results from the survey. Half of the respondents had made use of their ideas for inspiration in their existing teaching practices and half mentioned more concrete applications, 
such as publishing in higher education journals, introducing new teaching activities, and changing the curriculum.

\section{Teaching down-prioritized}

The Swedish higher education system makes academics torn between tasks and since the system makes them prioritize research from teaching, collegiality is at stake. Heavy workloads with increased management and administrative responsibilities are exacerbated by lack of time and resources: 'Resources are too scarce. It affects the possibility to cooperate and collaborate [about education].' (Education)

Widening perspective on teaching and research

All respondents claimed that participating in the sharing culture of professional development courses in higher education teaching and learning have an impact on their view on how they teach, such as verifying their current teaching practice, getting new ideas for their teaching, acquiring new angles to pedagogy, and broadening their perspective to teaching.

The courses have also brought a widening perspective of educational research and what research on teaching and learning in higher education entails.

I thought that it was interesting how persons belonging to other faculties looked upon teaching. [...] it has to do with many things such as the subject, discipline and who you are and who you teach. I thought it was interesting when we talked about the difficulties of meeting students and then I realized that we had different views. (Education)

\section{Sharing data}

Concerning collaboration, the respondents claimed that sharing data is essential but difficult. Sometimes it is not feasible due to the nature of the data. For instance, qualitative data such as interviews can be difficult to share since it is targeting very specific questions or can be difficult to interpret: 'A lot of data is difficult to interpret and you need to know the patient cohort, why a certain study has been done and how it should be interpreted.' (Medicine)

Another impediment is that it is sometimes not possible to share data due to ethical restrictions:

In collaboration with medicine, it is very restrictive since it has to do with patient security in different forms. Here I am steered by the ethical guidelines of what may and may not be disclosed. (Social Sciences) 
On the more positive side, ethical and democratic reasons for sharing data were brought up, where sharing was suggested to provide a broadened and enhanced analysis:

The data we have gathered is valuable and should be used fully. I think it is our responsibility to use it fully. We cannot expose ill persons for unnecessary testing and questioning, but should instead use the data we already have, fully. (Medicine)

I see myself as financed with tax money and what I do during my working hours should benefit society. (Social Sciences)

\section{Finding time for collegial reflection}

Teachers also have to find time for collegial reflection and engagement in transforming the curricula, something that is largely dependent on individual academics and not built into the system.

As well as collaborating in a research team, collaborating with colleagues about teaching is suggested to give new perspectives and critically question how teaching is being done and therefore increases quality. Further, on a more personal level, it is more fulfilling to collaborate with others as expressed by a respondent: 'You get oxygen and grow as a person.' (Education)

\section{Publishing open access}

The respondents were generally positive to publishing open access (OA) although other aspects may take precedence over openness, such as high quality, reputation, and impact factor. Ten of the respondents were already publishing OA or had considered publishing OA to make their research accessible to a wider audience. Out of the six who had not published OA, two were not working as researchers and the remaining four argued they have a different publishing culture. Six of the respondents brought up the economic aspects for the author of publishing OA as speaking against publishing $\mathrm{OA}$.

\section{Using digital tools for learning}

There is an interest by some respondents in digital tools for learning. This example shows how a course has been transformed to an online format to reach more students, a collaborative effort at the department:

For our beginner course in ancient Greek, about $90 \%$ are distance students. [...] there would be no more Greek at the university if we did not offer online participation. (Humanities) 
When resources are cut due to few campus students in narrow subject areas, teachers have to be creative in finding new ways forward. The above example from Ancient Greek, which was on the verge of being shut down with only a few campus students, has survived when being expanded through an online option.

Nine respondents out of the 16 created digital learning materials, four had committed themselves to vast development projects with online study materials as well as complementary online resources. Seven respondents did not engage much in digital tools, apart from basic digital practices necessary to perform the work as an academic at a university.

\section{Sharing outside university}

Most respondents were engaged in public outreach activities and found these activities an important part of their responsibility. A wide range of activities were mentioned, such as giving public courses or lectures outside of university, printing books, blogging, being on the radio and other media, and giving advice to organizations. The respondents had different attitudes towards collaboration with society, such as being part of the teachers' obligations or being of personal interest:

[...] research should not only turn inwards towards the research community. (Sciences)

I am one of the bloggers at my department's blog and I also participate in the media quite often. I was one of the experts on Swedish radio's panel covering the recent election results, I like to be in radio so I usually say yes. (Social Sciences)

\section{Mutual views on teaching and learning}

The results from the interviews show that academic teachers from different disciplines have mutual views on teaching and learning in higher education. However, from the respondents' statements, we could also identify expressions of identity and discrepancies in value. Although resources are scarce, academics see the essence of collaborating with others in, for instance, open sharing and digital tools for learning. They emphasize courses in teaching and learning as arenas for professional development and collegial exchange and stress the importance of engaging in collaboration with society.

\section{Discussion}

Societal change, such as complex problems that follow neither national nor disciplinary boundaries (Gilbert, 2016; Nowotny et al., 2001; Wals, 2007), gives reasons for rethinking or transforming 'ways of doing' in universities. Digitization 
is not only a facilitator for sharing across boundaries but also enabling societal change with large implications for higher education such as being more inclusive (Wals, 2007) and at the same time increasing the risk of making education more individualistic and alienated (Castañeda \& Selwyn, 2018).

Universities are unique in the sense that they both produce new knowledge and train future knowledge producers. The latter is a task that no other institution undertakes and therefore universities have a unique role in transforming both education and research so that they become each other's leverage in that transformation. Based on the results of this research, we argue that higher education teachers are open to changes and prepared to engage in a transformation of higher education. From the interviews, it seems that teachers are not only engaged in affirmative changes but in more transformative responses that address the root causes to various problems and make real changes. Based on the data, we suggest that a sharing culture is such a paradigm shift that universities have to engage in for such transformation to take place.

The testimonies do not give a clear picture of the epistemological assumption across disciplines, which can be a sign of difficulties articulating their epistemology since it is a kind of tacit knowledge. The respondents had a reflective understanding of what knowledge can be, and that there are different ways to create knowledge and to learn. Already in the 1970s, Kuhn argued that traditional sciences rely on particular ways of knowing based on data that are not always fixed and absolute, since the way the questions are asked and how data is collected affect the knowing and the interpretation of data is influenced by power relations and shared views (Hyland \& Kilcommins, 2009). Our data suggests a disruption of the traditional power relations between teachers and students in involving students in research, giving them a voice and tools to analyse and question our assumptions and problem definitions (Dewey, 1916). Student representation pertains to boundary-setting in higher education - by being included in the choice of literature and in the analysis of knowledge students are better able to contribute in creating new ways of doing in universities.

In spite of differences in teaching methods identified by the survey, our data provide a picture of university teachers from different disciplines sharing similar assumptions about teaching and learning, such as combining both transmission of knowledge in lectures and development of knowledge in student-centred learning activities, using both of the two metaphors of learning 'acquisition and participation' (Sfard, 1998) and combining teacher-focused and student-focused approaches (Trigwell, 2001).

To our second research question of what academics' views are on exchange within, between and beyond existing disciplines, the survey indicated that higher education is increasingly blended through a combination of face-to-face meetings and use of digital technologies and that it includes teaching across the boundary between academy and society. This type of boundary crossing may improve our 
ability to predict and form the future and is connected to Shulman's argumentation from 1999 that learning is most powerful when it can be tested, examined, challenged, and improved before we internalize it.

The interviews pointed at a general desire to share. Teachers from different disciplines highlighted a variation of methods for sharing across boundaries between disciplines as well as across the boundary between the university and the society. There were differences between disciplines in openly sharing data and some respondents emphasized that this sometimes is impossible due to ethical issues. In a study by Tenopir et al. (2011), open sharing of data was also reported in many different disciplines such as environmental sciences, physics, social sciences, and IT. Open sharing through open access journals was more common in hard disciplines which is in line with the literature from the field of medicine that several years ago started demanding open access publishing as a requirement for funding (Björk \& Solomon, 2012). Some teachers were critical of resource allocation (such as time for collaboration and money for open access publication) for new sharing initiatives to take place at a more general scale.

With respect to the third research question, it was found that the underlying aim of sharing was perceived to be learning to create new ways of thinking and teaching. The findings indicate that new knowledge develops out of collaboration; results that could not necessarily have been predicted before the start of the collaboration and thus opposed to commissioned research. Open sharing of knowledge at the boundary has been described by Engeström and Sannino (2010) as a transformative type of learning based on collaboration across sites. Generally, higher education has been described in a steady move towards greater interconnectedness and interdependence (Blessinger \& Anchan, 2015) and have engendered a loosening of disciplinary boundaries in the development of new curricula (Hannon et al., 2018). The introduction of digital technologies has been powerful in that transformation of higher education, and open sharing through peer production that utilizes the interactive potential of the Internet, Web 2.0, is one kind of trading zone for sharing that we want to highlight based on the results.

The data also made evident that there is a trading zone inherent within continuing education teaching and learning courses for colleagues from different disciplines. Our respondents reported that the courses not only were eye-opener for how they can rethink the way they teach but also for their perception of knowledge and teaching. In fact, the trading zone in which exchanges take place also provided the tools, such as a new 'language', that make exchanges possible. Thus, teachers share their epistemological assumptions and perspectives on teaching as well as research methodologies with colleagues, which is the horizontal direction according to Engeström and Sannino (2010). Exemplified by views on ethics related to open sharing, the trading zones are also used for sharing vertically, which is more about identity and moral commitments (ibid.) and about how disciplines value differently 
the forms of evidence and argument for a certain pedagogy in their effort to address concerns in their teaching practices.

\section{Limitations}

This study is focusing on teachers in higher education. Further studies could explore how students from different disciplines view disciplinary delimitations and sharing and how they can voice their rights and inquiries.

We rely on academic scholars self-reporting their own experience and understanding of their subject area and views on teaching and learning. They are expected to have a special interest in pedagogy and may not represent the average teacher. Further, the teachers may have been assigned to a specific teaching approach, for example lecturing which, in turn, may affect the data and therefore not reflect the teacher's personal view on teaching and learning.

\section{Conclusion}

Teachers in higher education understand the value of sharing across boundaries as a way forward for universities to expand and diversify their collective range of expertise to create robust and relevant knowledge and to keep its legitimacy in society. However, at system level universities may need to provide resources (such as time for collaboration and money for open access publication) to promote sharing across and beyond disciplines and thus scaffolding transformative changes.

The provision of trading zones between disciplines, exemplified with professional development courses in higher education in teaching and learning, open practices, and collaboration between academic disciplines and society, give teachers a new language to express their oftentimes tacit view on knowledge and teaching. Such trading zones can facilitate sharing among peers and have the potential to develop knowledge, identity and moral commitments necessary to address societal challenges.

\section{Acknowledgements}

We would like to thank all our colleagues from across our university who have contributed to our survey and interviews. We would also like to thank the editor and reviewers for careful reading, and constructive suggestions for our manuscript. 


\section{Author biographies}

Anne Algers is associate professor, conducting research and teaching at the department of Education, Communication and Learning and at the Pedagogical Development and Interactive Learning unit (PIL). She is also member of the advisory Board for Education for Sustainable development at GU. Her fields of expertise are Open education for social justice, Higher education teaching and learning, Scholarship of Teaching and Learning, Design based informal and formal learning, Digital literacy, Education for sustainable development, and Cultural historical activity theory. She has worked in multidisciplinary and transnational projects - for example in the fields of social justice and animal ethics.

Linda Bradley is associate professor, conducting research and teaching at the department of Education, Communication and Learning and at the Pedagogical Development and Interactive Learning unit (PIL). She is also international coordinator, (2020-) at the Faculty of Education, University of Gothenburg and Vicepresident (2012-) at the Research Publishing.net and co-editing annual conference proceedings for the EUROCALL conference. Her fields of expertise are Digital and mobile learning, Higher education teaching and learning, Scholarship of Teaching and Learning, Design based informal and formal learning, English for Specific Purposes, Mobile application research and development. 


\section{References}

Becker, T. (Ed.) (1989). Academic Tribes and Territories: Intellectual Enquiry and the Cultures of Disciplines. Milton Keynes: SRHE and OU Press.

Biesta, G. (2007). Why "what works" won't work: Evidence-based practice and the democratic deficit in educational research. Educational Theory, 57(1), 1-22.

Biglan, A. (1973). The characteristics of subject matter. Journal of Applied Psychology, 57(3), 195-203.

Björk, B. C., \& Solomon, D. (2012). Open access versus subscription journals: a comparison of scientific impact. BMC medicine, 10(1), 73.

Black, P., \& Wiliam, D. (2009). Developing the theory of formative assessment. Educational Assessment, Evaluation and Accountability (formerly: Journal of Personnel Evaluation in Education), 21(1), Article 5.

Blessinger, P., \& Anchan, J. P. (Eds.) (2015). Democratizing Higher Education: International Comparative Perspectives. New York and London: Routledge.

Castañeda, L., \& Selwyn, N. (2018). More than tools? Making sense of the ongoing digitizations of higher education. International Journal of Educational Technology in Higher Education, 15(1), 211.

Dewey, J. (Ed.) (1916). Democracy and Education: An Introduction to the Philosophy of Education. New York: Free Press.

Dewey, J. (Ed.) (1920). Reconstruction in Philosophy. New York: Henry Holt.

Engeström, Y., \& Sannino, A. (2010). Studies of expansive learning: Foundations, findings and future challenges. Educational research review, 5(1), 1-24.

Galison, P. (1997). Image and Logic: A Material Culture of Microphysics. Chicago: The University of Chicago Press.

Gardner, H., \& Shulman, L. S. (2005). The professions in America today: Crucial but fragile. Daedalus, 134(3), 13-18.

Gilbert, J. (2016). Transforming science education for the Anthropocene-Is it possible? Research in Science Education, 46(2), 187-201.

Hannon, J., Hocking, C., Legge, K., \& Lugg, A. (2018). Sustaining interdisciplinary education: Developing boundary crossing governance. Higher Education \& Research Development, 37(7).

Hyland, Á., \& Kilcommins, S. (2009). Signature pedagogies and legal education in universities: epistemological and pedagogical concerns with Langdellian case method. Teaching in Higher Education, 14(1), 29-42.

Kegan, R., \& Lahey, L. L. (Eds.) (2009). Immunity to Change: How to Overcome It and Unlock the Potential in Yourself and Your Organisation. Boston: Harvard Business School Press. 
Kember, D. (1997). A reconceptualisation of the research into university academics' conceptions of teaching. Learning and instruction, 7(3), 255275.

Kreber, C. (2009). Different perspectives on internationalization in higher education. New directions for teaching and learning, 118, 1-14.

Kuhn, T. S. (Ed.) (1962). The structure of scientific revolutions. Chicago and London: University of Chicago Press.

Laurillard, D. (Ed.) (2012). Teaching as a design science: Building pedagogical patterns for learning and technology. New York and London: Routledge.

Meyer, J. H., \& Land, R. (2005). Threshold concepts and troublesome knowledge (2): Epistemological considerations and a conceptual framework for teaching and learning. Higher education, 49(3), 373-388.

Mills, D., \& Huber, M. T. (2005). Anthropology and the educational 'trading zone' disciplinarity, pedagogy and professionalism. Arts and Humanities in Higher Education, 4(1), 9-32.

Nicola-Richmond, K., Pépin, G., Larkin, H., \& Taylor, C. (2018). Threshold concepts in higher education: A synthesis of the literature relating to measurement of threshold crossing. Higher Education Research \& Development, 37(1), 101-114.

Nowotny, H., Scott, P., \& Gibbons, M. (Eds.) (2001). Rethinking Science: Knowledge and the Public in an Age of Uncertainty. Cambridge, UK: Blackwell Publishers.

O'Donnell, R. (2010). A critique of the threshold concept hypothesis and an application in economics. University of Technology, School of Finance and Economics. Working Paper, 164.

Peel, D. (2011). Signature pedagogies and the built environment. Journal for Education in the Built Environment, 6(2), 1-7.

Prosser, M., \& Trigwell, K. (Eds.) (1999). Understanding Learning and Teaching: The Experience in Higher Education. Buckingham: SRHE and Open University Press.

Prosser, M., Martin, E., Trigwell, K., Ramsden, P., \& Lueckenhausen, G. (2005). Academics' experiences of understanding of their subject matter and the relationship of this to their experiences of teaching and learning. Instructional Science, 33(2), 137-157.

Rotidi, G., Collins, J. B., Karalis, T., \& Lavidas, K. (2017). Using the teaching perspectives inventory (TPI) to examine the relationship between teaching perspectives and disciplines in higher education. Journal of Further and Higher Education, 41(5), 611-624.

Sfard, A. (1998). On two metaphors for learning and the dangers of choosing just one. Educational researcher, 27(2), 4-13.

Shulman, L. S. (2005). Signature pedagogies in the professions. Daedalus, 134(3), 52-59. 
Shulman, L. S. (1999). Taking learning seriously. Change: The Magazine of Higher Learning, 31(4), 10-17.

Tenopir, C., Allard, S., Douglass, K., Aydinoglu, A. U., Wu, L., Read, E., ... \& Frame, M. (2011). Data sharing by scientists: practices and perceptions. PloS One, 6(6), e21101.

Thomas, D., \& Brown, J. S. (Eds.) (2011). A new culture of learning: Cultivating the imagination for a world of constant change (Vol. 219). Lexington, KY: CreateSpace.

Trigwell, K. (2001). Judging university teaching. International Journal for Academic Development, 6(1), 65-73.

Trowler, P., Saunders, M., \& Bamber, V. (Eds.) (2012). Tribes and territories in the 21st century: Rethinking the significance of disciplines in higher education. London: Routledge.

Wals, A. E. (Ed.) (2007). Social Learning: Towards a Sustainable World: Principles, Perspectives, and Praxis. Wageningen, The Netherlands: Wageningen Academic Publishers.

Ödalen, J., Brommesson, D., Erlingsson, G. Ó., Schaffer, J. K., \& Fogelgren, M. (2018). Teaching university teachers to become better teachers: The effects of pedagogical training courses at six Swedish universities. Higher Education Research \& Development, 38(2), 339-353. 


\section{Appendix 1. Survey and interview questions}

Survey questions

1. Which Department do you belong to?

2. In which discipline / subject (subjects) do you work?

3. How many years have you been teaching in higher education?

$$
\begin{aligned}
& 0-1 \text { year } \\
& \text { 2-5 years } \\
& \text { 6-10 years } \\
& \text { more than } 10 \text { years }
\end{aligned}
$$

4. What do you use in your teaching (more options possible): (Lecture, Seminar, Group work, Workshop, Lab, Case-method, Roleplay, Exercise, Flipped classroom, Student presentation, Peer response, Problem Based Learning, Response technology exercises, Other)

5. I have the following views regarding openness in my work. Specify those applicable (more options possible):

I share my ideas with my colleagues

I share my data openly on the internet

I have published in open access journals

I reuse others' materials

I do not work actively for openness

Other

6. How higher education pedagogy is discussed within my discipline (Likert scale; I strongly disagree, I disagree, I am neutral, I agree, I fully agree)

I discuss pedagogical questions with my colleagues at my department I discuss pedagogical questions with my colleagues outside of my department

7. Below you find 5 short statements about pedagogical principles, based on Laurillard (2012). Please, specify to what degree these statements match your teaching situation (Likert scale; I strongly disagree, I disagree, I am neutral, I agree, I fully agree)

I align the learning objectives to students' earlier experiences I use assessments to tap understanding, not facts, isolated skills nor surface knowledge

I use formative assessment to make student's thinking visible during the learning process 
I provide theoretical exercises with tasks and feedback that reveal student thinking

I encourage meta-cognitive discussions about content

8. Did the courses in higher education teaching and learning contribute to knowledge about teaching methods that you were not aware of before and which you use today? (one option possible)

Yes, through the course activities

Yes, through other course participants

Yes, through both course activities and other course participants

No, I did not learn any new teaching methods that I did not know of before

Other

9. Did the courses in higher education teaching and learning contribute to knowledge about pedagogical perspectives to learning that you were not aware of before? (one option possible)

Yes, through the course activities

Yes, through other course participants

Yes, through both course activities and other course participants

No, the courses did not contribute with any new perspectives that I did not

know of before

Other

10. Have you implemented your idea from your independent work in the courses in higher education teaching and learning and, if so, can you briefly describe the impact it has had?

11. Is there anything else you would like to add?

Interview questions

1. Discipline?

2. When did you defend your thesis?

3. How many percent of your employment is devoted to research?

4. How long have you been teaching at university level?

Research: Ways of knowing

5. Do you collaborate with colleagues on research within your discipline? outside of your discipline? How? Why? What is your view about such collaboration? For your: discipline, unit for yourself? 
6. Do you share data with colleagues from your discipline? Outside of your discipline? Give examples. What is your view about sharing research data? Pros and cons?

7. Do you publish in open access journals? Why /why not?

8. What is knowledge?

9. Did the PIL-courses change your view on knowledge?

Education: Ways of teaching

10. What is good teaching?

11. Did the PIL-courses change your view on teaching?

12. Do you collaborate with teachers inside/outside of your discipline? How? Why? What is your view about collaboration on teaching? For your discipline and for yourself?

13. How do you disseminate your educational work among colleagues?

14. Do you engage in public outreach or contract teaching? Give examples

15. Do you engage in development of digital learning material for your courses? (solitary or in collaboration?) Why? Give examples.

16. Do you use external online resources in your teaching? How? Why? Give examples.

17. Do you assist students in using digital resources in teaching your students? How? Why? Give examples.

18.Have you made use of your pedagogical ideas from the courses? If yes, how? (For your discipline and for yourself)

19. Has your understanding of research and teaching in higher education been influenced by your collaboration with other colleagues from other disciplines in the courses? If yes, how? (For your discipline and for yourself) 